\section{Analysis of basic building performance data for identification of performance issues}

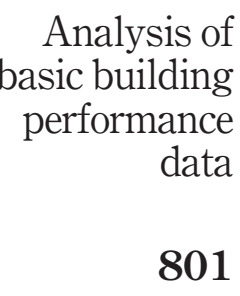

Tristan Gerrish

Centre for Innovative and Collaborative Construction Engineering, Loughborough University, Loughborough, UK and Buro Happold Ltd, Leeds, UK

Kirti Ruikar

School of Civil and Building Engineering, Loughborough University, Loughborough, UK

Malcolm Cook

Department of Civil and Building Engineering, Loughborough University, Loughborough, UK, and

Mark Johnson and Mark Phillip BuroHappold Engineering, Leeds, UK
Received 10 January 2016 Revised 3 May 2016 Accepted 29 July 2016

\begin{abstract}
Purpose - The aim of this paper is to demonstrate the use of historical building performance data to identify potential issues with the build quality and operation of a building, as a means of narrowing the scope of in-depth further review.

Design/methodology/approach - The response of a room to the difference between internal and external temperatures is used to demonstrate patterns in thermal response across monitored rooms in a single building, to clearly show where rooms are under-performing in terms of their ability to retain heat during unconditioned hours. This procedure is applied to three buildings of different types, identifying the scope and limitation of this method and indicating areas of building performance deficiency.

Findings - The response of a single space to changing internal and external temperatures can be used to determine whether it responds differently to other monitored buildings. Spaces where thermal bridging and changes in use from design were encountered exhibit noticeably different responses.

Research limitations/implications - Application of this methodology is limited to buildings where temperature monitoring is undertaken both internally for a variety of spaces, and externally, and where knowledge of the uses of monitored spaces is available. Naturally ventilated buildings would be more suitable for analysis using this method.

(C) Tristan Gerrish, Kirti Ruikar, Malcolm Cook, Mark Johnson and Mark Phillip. Published by Emerald Publishing Limited. This article is published under the Creative Commons Attribution (CC BY 4.0) licence. Anyone may reproduce, distribute, translate and create derivative works of this article (for both commercial and non-commercial purposes), subject to full attribution to the original publication and authors. The full terms of this licence may be seen at http://creativecommons.org/ licences/by/4.0/legalcode

This research was supported by EPSRC funding (EP/G037272/1) in conjunction with support from sponsors BuroHappold Engineering as part of an EngD research project at the Centre for Innovative and Collaborative Construction Engineering, Loughborough University.
\end{abstract}


$\mathrm{F}$

$35,13 / 14$

Originality/value - This paper contributes to the understanding of building energy performance from a data-driven perspective, to the knowledge on the disparity between building design intent and reality, and to the use of basic commonly recorded performance metrics for analysis of potentially detrimental building performance issues.

Keywords Performance measurement, Data analysis, Temperature, Facilities management, Building management, Post occupancy evaluation

Paper type Research paper

\section{Introduction}

Management of a buildings' operational performance for the purpose of providing a comfortable environment for its occupants is one of the primary aims of facilities management (FM). The inhabitants of a building are its end-users, and those who are most likely to notice when a particular aspect of its environmental conditioning is not performing to specification. In addition to occupant feedback, the most commonly used method of monitoring building performance is through use of building management systems (BMS), comprising a network of sensors, actuators and control system for the conditioning systems, with access to records of various aspects of a building's performance. The modern BMS is used to control systems for optimal energy use and occupant comfort, indicating current performance of equipment and spaces; however, review of historic information to support energy-use reduction efforts is less likely to occur, though becoming more common (Arditi et al., 2015).

Making use of the amount of information generated by a building throughout its day-today operation provides the opportunity to explore patterns of energy consumption, variation of temperature in response to internal gains and external weather, and the ability to identify where potential improvements may be made. While this may not be considered "big data", the amount of energy used in the heating of non-domestic buildings within the UK accounts for 50 per cent of the total energy consumption by these buildings (Waters et al., 2015). During 2010, the UK commercial offices used over 14,000 GWh, of which even small improvement in holistic building performance could yield significant reduction.

Identifying where improvements could be made here is possible at small scale using data collected during building use and continuous commissioning taking account of changing needs for heating, cooling and ventilation. Exploration and analysis of basic data sets describing building performance is commonly used to identify patterns of use, but analysis of these to provide insight into long-term trends imperceptible to visual inspection may provide a valuable source of intelligence in the management and improvement of ongoing building performance. As monitoring becomes more commonplace (Ahmad et al., 2016; Clements-Croome and Johnstone, 2013), the opportunities to do so increase, and so does the availability of data sets to indicate where improvements could be made.

\subsection{The performance gap}

The difference between how a building should perform according to its design specifications and how it does perform is widely known as the "performance gap". The reasons for this gap have been extensively researched (Bordass et al., 2001; Menezes et al., 2012; Zero Carbon Hub, 2014), leading to a greater understanding of the interaction between user and building, methods of providing a comfortable internal environment and education of the occupant to make effective use of a building and its controls. These factors are changeable through behavioural modification and changes to operational strategies (Martínez-Molina et al., 2016), whereas less behaviourally modifiable reasons such as the reduced quality of as-built 
fabric are more difficult to identify or change following construction (Way and Bordass, 2005). In the report by Zero Carbon Hub (2014), among all potential reasons for this "gap", build quality is included, of which four priorities were targeted to reduce discrepancy between prediction and use. These were:

- limited understanding by the designers of the requirements for a thermally efficient building (particularly in regard to detailing);

- procurement of inadequately skilled labour, resulting in poorly finished detailing, leading to air tightness and thermal bridging issues;

- substitution of products on-site leading to less thermally efficient materials and improvised modifications detrimental to fabric performance; and

- poor fabric installation potentially raising the U-value by up to 250 per cent (Hens et al., 2007).

Research by Theodosiou and Papadopoulos (2008) showed that thermal bridging contributed to greater heat losses than otherwise encountered in spaces without such construction defects. Doran and Carr (2008) demonstrated that following retrofitting of insulation in poorly insulated residential buildings, the internal and external temperature difference increased by approximately $0.5^{\circ} \mathrm{C}$. These studies examine in depth the effects of thermal bridging and insulation on space temperatures, but both required extensive investigation and monitoring of specific elements within those spaces, and therefore, there is a significant amount of effort in implementation and analysis (White, 1989). These investigations may be considered a form of post-occupancy evaluation (POE), where instead of using long-term building performance data, short-term yet high-resolution monitoring is used to determine fabric-element performance. In these studies, the amount of heat lost through these thermal bridges is often greater than expected (Marincioni et al., 2015), but slight variation in building fabric quality may not be shown through visual inspection of records without access to thermal imaging equipment.

\subsection{Post occupancy evaluation}

Investigation of monitored building-performance information can provide a means of understanding of the reasons behind why a building performs as it does, indicating potential faults and opportunities for improvement (Menezes et al., 2012). The process of investigating this data, among evaluation of the ways in which the building is used and how its occupants feel within it, is the purpose of POE, with a view to better managing building-systems operation for improvement in efficacy and in many cases managing occupant expectations (Brown and Cole, 2009). In the UK, POE has been referenced in recent initiatives to improve in-use operational efficiency as part of a Soft Landings policy (Way et al., 2009), but while the handover of a building and proper operation of its systems contribute to the overall performance of the building, the buildings fabric plays a large part in this performance. Most POE studies identify the factors contributing towards poor building energy performance (Bordass et al., 2001), demonstrating the main reason in most cases to be improper use of the building systems and spaces (Pegg et al., 2007). Further schemes to use for the evaluation of buildings in a larger context to identify trends are also implemented (DOE et al., 2016; The AECB, 2013; The Digital Catapult and Innovate UK, 2016), but again focus on holistic performance without aggregation of data sets in which these performances could be contextually analysed. While construction quality is mentioned as a contributing factor to potential performance defects from designed expectations, methods of identifying
Analysis of basic building performance data

803

$-$


$\mathrm{F}$

$35,13 / 14$

804 where fabric may be causing a significant effect on internal conditions (and therefore energy used to condition these spaces) are limited.

Currently, the main methods of identifying the faults in construction or the effect that expected wear and tear throughout a buildings use contribute towards a potential deficit in performance Mydin et al. (2012) are walk-round surveys and continuous operations and maintenance records. Building fabric inspection during walk-round surveys and the use of thermography to identity cold-spots where thermal bridging, insufficient or deteriorated insulation may be present (Taileb and Dekkiche, 2015) take time, and given the need to further investigate each potential problem can become a major inhibitor to the full evaluation of a building during POE (Preiser, 2003). In some cases, problems may be missed because of inaccessibility, for example, in non-visible or difficult to access areas such as roofs or behind cladding. However, even technology such as thermal imaging cannot see through walls, and rely on emitted radiation for which, in cases such as thermal bridges around glazing, may not be easily identifiable (Fox et al., 2014). In these situations, the measurement of descriptive space performance aspects is often the next step in identifying why a performance characteristic is being perceived and where "big data" style analytics could be applied to historical building performance records to provide useful insight.

\subsection{Performance monitoring and interpretation}

Monitoring of space temperatures in conjunction with knowledge of a building's operational strategy can indicate where potential issues in those monitored spaces may be occurring. For example, a space that does not increase in temperature during a period where the heating in that space is active could indicate a closed valve, a non-responsive sub-system or faulty sensor (Ahmad et al., 2016). Within a large building where there are likely to be several sensors recording multiple aspects in each monitored space, including monitoring of heating, ventilation and air-conditioning (HVAC) equipment, and extracting meaning from such expansive data sets can become difficult (Zhou et al., 2016).

Many difficulties occur when accounting for errors. Typically, a problem with the building is reported, requiring investigation to which historical monitored performance is referenced (Kim et al., 2009). Knowing the location of a potential issue enables the investigator to narrow the review of records to adjacent and related areas, shortening investigation time. If the issue is not identifiable in this way (or is too slight to give a clear distinction of under-performance), there is very little the investigator can use to remediate that performance inhibitor (Djuric and Novakovic, 2009).

Use of BMS performance records to suggest opportunity for performance improvement demonstrate this problem well. A building may be monitored across all measurable metrics; however, without a defined scope in which potential issues can be identified, there is less likelihood of distinguishing normal levels of performance from that outside reasonable expectation (Seem, 2007). Lessons may be learned from outside construction subjects, where Levac et al. (2010) suggests that clarification of purpose, process and interpretation can maximise the usefulness of analysis. Here, automatic recognition of faults and errors is useful in areas where the range of expected monitored variables is known and in which patterns and trends can be quantified. Fault detection and diagnosis is prevalent in HVAC equipment monitoring (Capozzoli et al., 2015), but in space temperature monitoring, there is limited research due to the number of factors contributing to a building's thermal response. Pattern recognition can however be used to suggest potential faults where the user does not know where to start or if the data used are extensive enough for some patterns to be found (Peña et al., 2016). 
Automatic recognition of errors in building conditioning have been developed (Katipamula and Brambley, 2005; Khan et al., 2013), but these mostly apply to specific pieces of equipment where ranges of expected operation are given, outside of which an alarm is triggered. Similarly, spaces can be monitored where excess temperature triggers an alert to the FM to investigate, but these are less common given that building services monitoring would likely preclude this via measurement of the systems providing those conditions. Long-term monitoring overlooks faults with building fabric that may have little immediately identifiable effect on energy consumption, but it contributes to excess energy consumption. For example, an individual space using significantly more heating than others may not be recognised as part of regular monitoring as it may be only part of a group of spaces, or where changes are subtle and performance reduction is not noticed.

In addition to unrecognised errors, gaps in data are another area where limits are imposed on analysis of space temperature performance. Baltazar-Cervantes and Claridge (2002) demonstrated means of rectifying errors in time-series temperature records, with $\mathrm{Hu}$ et al. (2014) furthering this for longer-term gaps. As technology now allows monitoring and storage of longer term records (Kim et al., 2011; Yu et al., 2015), gaps in data become less impacting, given the breadth of context made available. Through aggregation of records and accessibility of larger descriptive data sets, the potential for errors and gaps increases, but are also more discountable because of the range of data with which to compare. However, with that larger amount of data, analysis is also then susceptible to interpretation errors such as confirmation bias and causation/correlation misrepresentation (Taleb, 2013).

\section{Method}

The relationship between internal and external temperature, and the difference between these are investigated, using the rate of change for each to derive potential construction quality or internal conditioning issues within the monitored spaces. In this approach, historical records describing space temperature data are used to show the rate of change in temperature over time, as a function of the difference between external and internal temperature. While this is limited to periods outside normal conditioned hours (as during occupied hours' occupants, lighting and equipment use can alter internal temperature significantly), it shows a subtle distinction of spaces under and over-performing in terms of their heat loss.

\subsection{Test cases}

Three buildings were used in the development and testing of this method, demonstrating its potential and limitations. Each building is a different type (domestic, non-domestic office and non-domestic school), in which operating conditions and schedule differ significantly, given their purposes. Each has temperature monitoring within several spaces, providing a record over at least one full year and external temperature recorded on each site to provide external context. These buildings were chosen primarily because of availability of their internal space temperature data and as a range of test cases in which the method could be evaluated against varying conditions. These were: limited number of monitored spaces; differences in occupied hours; location and external temperature variation conditions; and method of heating, cooling and ventilation. Floor-plans for each of these buildings are given in Figure 1, with some spaces labelled.

2.1.1 Residential. The residential building is a three-storey dwelling located in south-east England, recently refurbished to provide greater insulation, airtightness and heating system efficiency. Hours of operation (where occupied and assumed heated) were between 17:30 and 09:00. The composition of this building is typical of residential buildings in the UK, 
$\mathrm{F}$

$35,13 / 14$

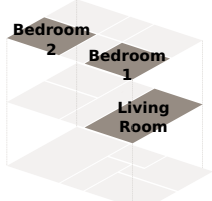

(a)

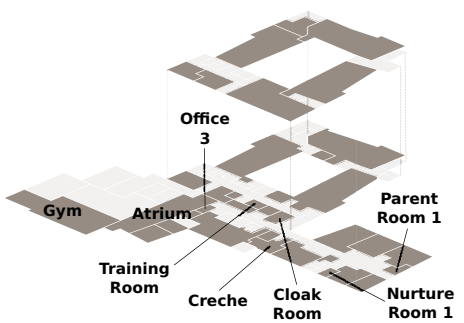

(b)

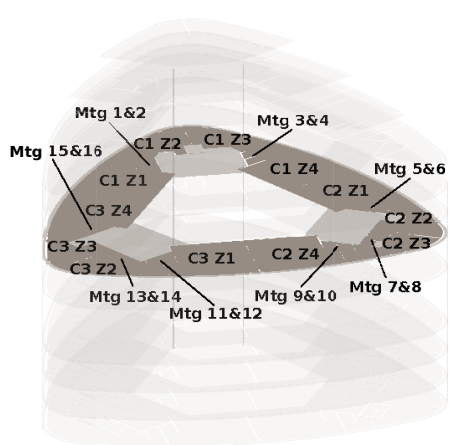

(c)

Figure 1. floor plans

Notes: (a) Residential; (b) School; (c) Office

comprising non-insulated cavity walls, though during refurbishment this was supplemented with expanded polystyrene added to the external cladding with space heating provided by a gas central heating. Data for this building were available for a full year (June 2012-May 2013) at hourly intervals. Previous studies by Dowson (2012) on this same building showed an improvement in performance following refurbishment, though this was less than expected in some areas, potentially because of poor construction quality. Thermal bridging was also identified in the living room space using thermography, showing the link to the adjacent house as point of greater than usual heat loss.

2.1.2 School. The school building is a primary school completed in 2014 and located in the north of England. This building received a BREEAM "Excellent" rating and comprises a two-storey conventional rain-screen clad, brick and mortar naturally ventilated and built with spaces dedicated to teaching, childcare and administration. Occupied hours were between 08:00 and 18:00, heated correspondingly with a ramp-up period from 07:00. Data for this building were available for 19 months (September 2014 -April 2016) at 15-minute intervals. A full POE is being conducted on this building after occupants described problems with overheating and trouble maintaining stable temperature in several spaces. During a preliminary walk-round survey, no immediately visible problems were noted, indicating that the rooms were improperly conditioned, nor were there behavioural issues noted, such as interaction with equipment or window opening when that would cause such problems.

2.1.3 Office. The office building is a high-performance office located in the north of England and completed in 2013. It comprises 14-storeys (of which 9 are repeated floor-plans) and uses a double-skin façade to minimise solar gain during summer and provide a means of preheating supply air during winter. The building is occupied between 08:00 and 19:00, with heating provided via conditioned air through plenum variable air volume (VAV) boxes into perimeter heated spaces and passive chilled beams for cooling. Each repeated floor comprises mainly of open-plan spaces, with meeting rooms and small server rooms around a central atrium, into which cross-ventilation was planned during design. Data were available for this building at 30-minute intervals between August 2014 and March 2016. All spaces were monitored throughout the building; however, in several, errors in recording meant data were unsuitable for analysis, resulting in a subset of the total spaces where data were available being used. 


\subsection{Data collection and processing}

Prior to data analysis, significant amounts of pre-processing were undertaken to ensure the data were suitable for analysis without potential for erroneous records to influence results. Python was chosen as the language used to parse, transform and output results from the historical temperature records, using the Pandas package (McKinney, 2010), because of its time-series data handling capabilities.

For each building the time-series data were sorted according to its time-stamp and resampled to a common interval. For example, where records logged non-uniform interval data, records were made uniform with the corresponding values linearly interpolated to fit. In all buildings, the data were re-sampled to half-hourly intervals for ease of comparison, and where gaps larger than two-intervals were found, these were left null to prevent incorrectly estimated data impacting the analysis outcome. Errors, such as values outside reasonably expected limits because of faulty or incorrectly calibrated sensors, were accounted for by removing values outside the winsorised mean between the 10th and 90th percentiles \pm 10 standard deviations.

Seasonality was not accounted for here, meaning any time periods where there was a disproportionate representation of different seasons (for example, where data represented one winter and two summer periods) was not tested for; however, given the number of individual days in which the following method was applied, this would have little effect on the outcome.

2.2.1 Temperature difference/change in temperature difference. The difference between the internal (Ti) and external (To) monitored temperatures is the basis of this analysis. While external temperature drops, the amount of energy required to maintain a specific internal temperature above the outside value under the same level of internal gain increases. In this analysis, we are not looking at energy consumed by HVAC systems, only the response of the room once these systems have been switched off. Therefore, after completion of the analysis, the hours used to identify potential differences in space composition or use are limited to those directly after heating (as all buildings here are in a primarily heatingbased climate) has been switched off.

A typical daily room temperature profile for the school is shown in Figure 2 compared with external temperature, showing that as the heating switches off at 18:30 (and cleaners leave shortly after this at around 19:15), the internal temperature drops in proportion with the drop in external temperature. This is primarily because of losses through fabric in conjunction with loss to adjacent, cooler spaces within the building. If the building is uniformly conditioned and of the same composition and construction quality throughout, each space would be the same temperature at this point, meaning an externally adjacent space would lose heat faster than internal spaces. In the figure, a sharp drop in internal temperature can be seen on 20 May, most likely as a result of an open window, demonstrating the impact of user behaviour on the monitored conditions within a space.

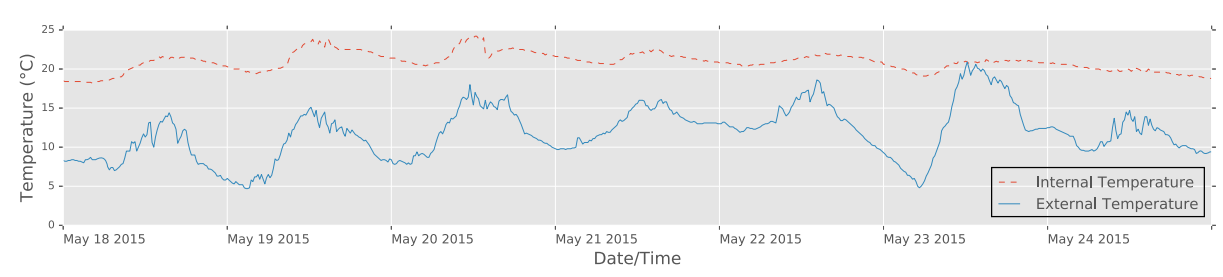

Figure 2.

Typical diurnal internal temperature response to external temperature and HVAC conditioning (for school base room 5) 
F

$35,13 / 14$

808

Figure 3.

Difference between internal and external temperatures and the rate of change at each time-step (for school base room 5)

\section{Figure 4.}

Scatter plot showing the gradient of the difference in temperature plotted against the difference in temperature at the same point in time (for residential living room)
Conversely, the lack of user interaction in unheated spaces over the weekend, show the gradual loss of heat through conduction and infiltration as the space returns to ambient conditions.

For all monitored rooms, the difference between internal and external temperature at each point in time sampled is calculated. As these tend to vary greatly because of the variability of both internal and external heat gains and losses contributing to this difference, the rate of change over time is also calculated using the gradient of this temperature difference (Figure 3). Decreasing the interval between sample points would smooth these results, but for the purposes of testing, a high sample rate is useful owing to the potential for inclusion of cumulative errors. The most important part of this data is the period after the conditioning is switched off to understand each monitored rooms response to a steadily decreasing external temperature.

Figure 4 shows a changing relationship over the course of the day by plotting these two values against each other for each sampled time. During occupied hours when heating is on and spaces are being used, the majority of spaces maintain a constant internal temperature
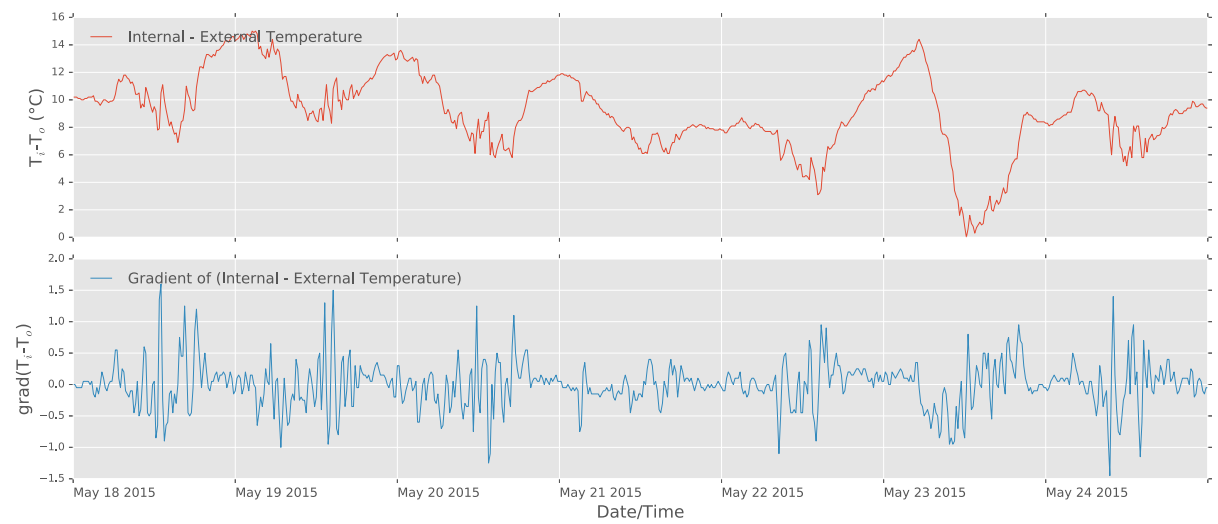
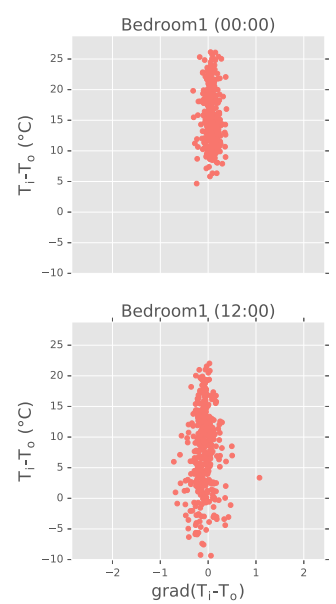

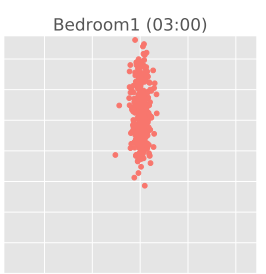

Bedroom1, (15:00)

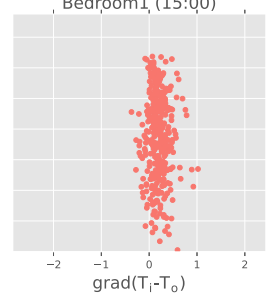

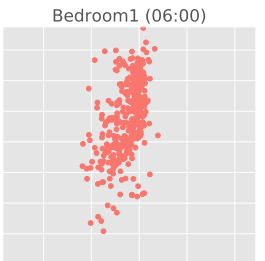

Bedroom1 (18:00)

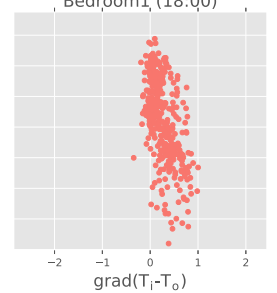

Bedroom1 (09:00)

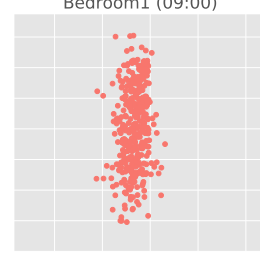

Bedroom1, (21:00)

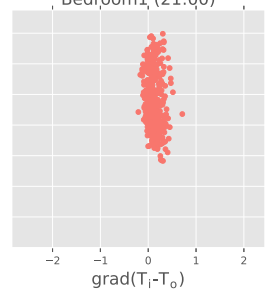


against a gradual change in external temperature. This results in a wider spread in these plotted points, and conversely a narrower spread after the heating is switched off, when the rate of change in internal temperature is a proportion of the rate of change in external temperature. Generally, a drop in temperature inside coincides with a drop in temperature outside, but in some cases, where internal gains are present, this can be seen as a wider spread of points during unoccupied or unconditioned hours.

Two mechanisms are being presented in Figure 4, showing that during cool-down hours (06:00-09:00 in the residential example), the greater the difference between internal and external temperature, the greater the rate of change in that temperature difference over time. During heat-up hours (18:00-21:00 in the residential example), the inverse is true, meaning the rate of change in temperature difference is greater at lower temperature differentials.

2.2.2 Average rate of change of temperature. For each room and at each sampled time, a slight relationship can be found between temperature difference and rate of change during times at the start of, and following conditioned hours. For each time period relationship illustrated in Figure 4, the average slope between all points gives a value for the rate of change in temperature that room experiences, as a function of the internal/external temperature difference. A line of fit with gradient above 0 shows a space heating up, with an increasing gradient demonstrating a faster response to changing temperature. A line of fit with gradient below 0 shows a space cooling down, with the magnitude of that negative gradient describing the speed of thermal response. Generally, a room with no building services intervention would be expected to respond to a decrease in external temperature with a slight lag and rate of change that initially increases, then decreases. Those spaces with potential problems in their conditioning or fabric would show a different response to other monitored spaces in the same building.

Plotting the average slope of each time-step in Figure 4 for each space shows a clear distinction between those spaces responding differently to the temperature difference than the rest of the monitored spaces. Figures 5-7 show how each monitored space in the three buildings compare with other spaces in the same building, in terms of their cooling and heating sensitivity to the rate of change of the internal and external temperature difference. The key periods after heating has been switched off are most interesting, as they show the spaces' response to changing temperature difference without additional influence from artificial conditioning and are indicated. The analysis period shown in each plot contains the data from which further statistical analysis is performed. Spaces outside the general trend are those potentially warranting further examination, and are those highlighted on each plot demonstrating their thermal response amidst all other monitored spaces. Average internal and

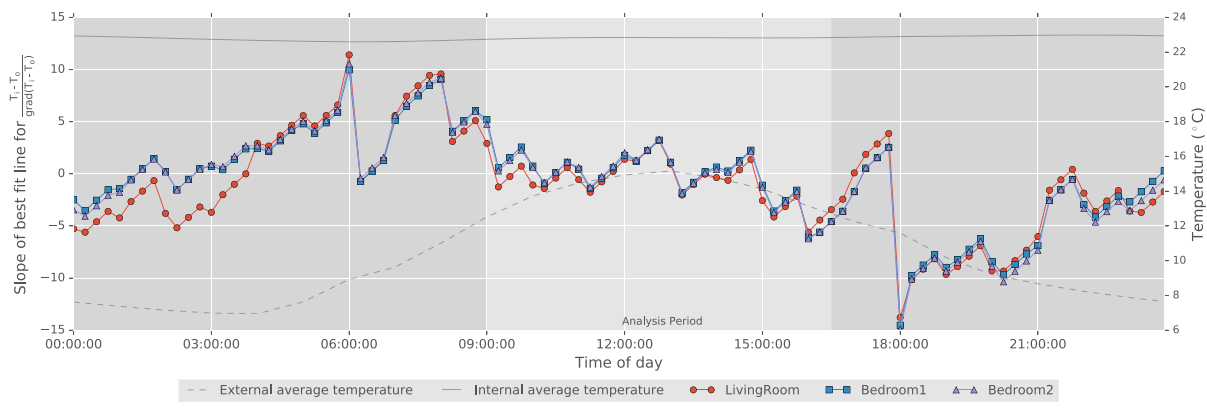

Analysis of basic building performance data

809

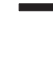


$\mathrm{F}$

$35,13 / 14$

810

Figure 6.

School building thermal response

Figure 7.

Office building thermal response external temperatures are also shown for context, with a small error in Figure 7 where the air-handling system starts at 06:00, resulting in greater airflow around the sensor and a noticeable drop in perceived external temperature.

Figure 5 for the residential building shows that the living room (where thermography showed thermal bridging against an adjacent, less efficient building) is marginally more susceptible to changing internal/external temperature difference than the other two monitored spaces. Similar patterns can be seen in the school (Figure 6) in the gym, atrium and Parent room 1, and in the office building (Figure 7) for Level 4 Meeting room 8. These indicate that each space is losing heat at a rate greater than the average of all other spaces. In the school, several spaces show significant difference from the average thermal response, notably the Crèche and Nurture Room 1 where occupant complaints had been noted during the POE. As these lose heat at a greater than average rate after occupied hours, they behave more thermally lightweight in response to conditioning during occupied hours, suggesting potential overheating.

The office building shows far lower variation in rate of temperature change during unconditioned hours as expected given its double façade configuration mitigating heat loss, and close control maintaining a setback temperature outside occupied hours. Spaces deviating from the normal pattern indicate another issue impacting that spaces temperature change, such as operational difference or change in use.
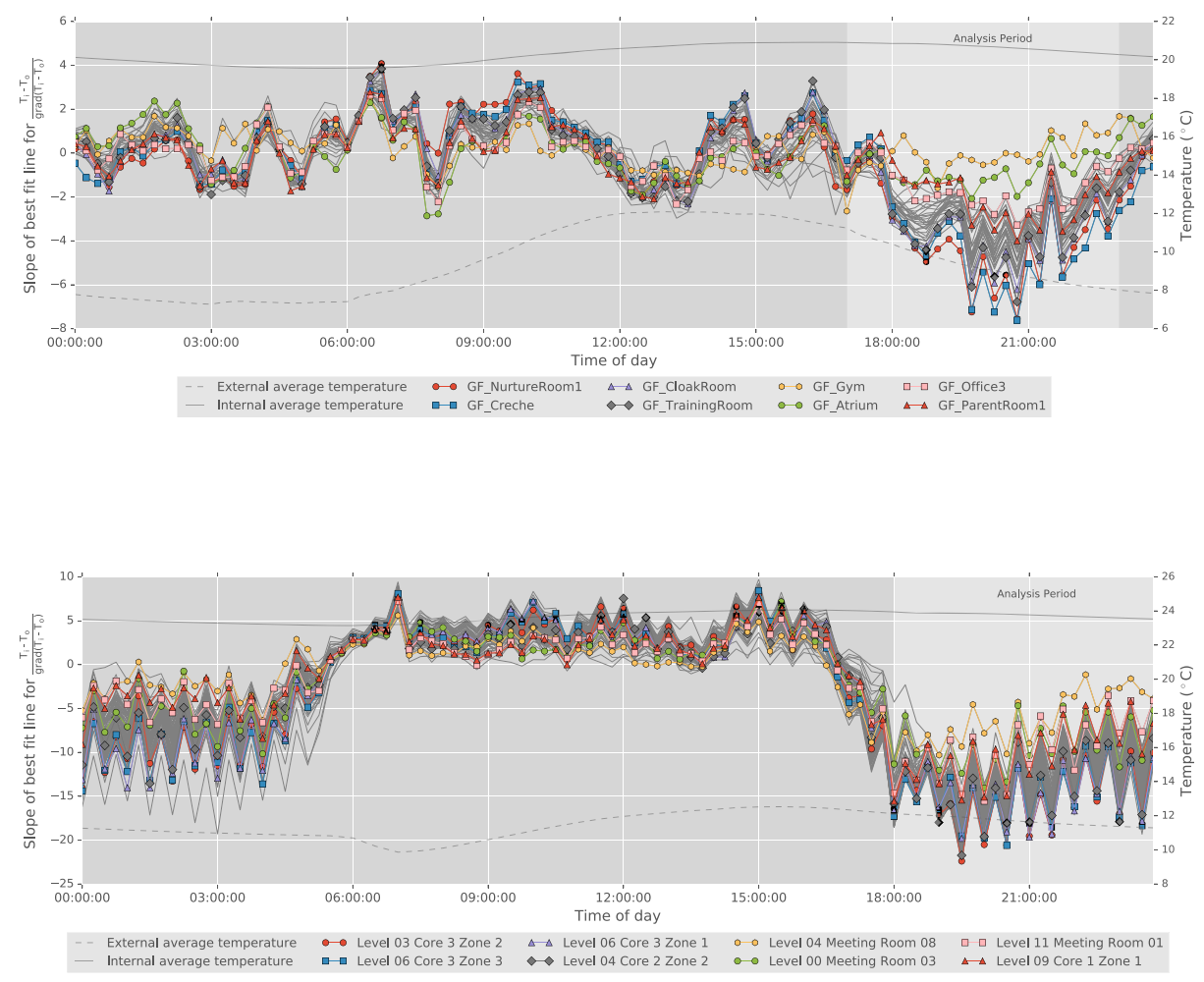


\section{Results}

As each room has a different purpose and use, each shows a slight difference from the average response of the entire building; however, those that are significantly different in terms of their response to changing internal and external temperature difference can be immediately identified. Each building is investigated to identify why these differences occur, and determine whether the quantification of the values portrayed in Figures 5-7 can be used to determine whether this difference is significant enough to warrant further attention. Quantification of difference is achieved through obtaining the average slope within the analysis period, for which linear regression is used to determine goodness of fit from those points within that period, shown in Table I.

Quantification of these results enable to investigator to quickly identify which rooms require most attention, using the average rate of change within the analysis periods. Confidence in the results shown so far has been overlooked in favour of visually comparing each space with the average. Arranging each monitored place in order of its average rate of change after occupied hours (when heating is switched off) shows those rooms where heat is lost at a greater and slower rate than others. The analysis periods here represent between 24 and 30 distinct measurements; however, given the changeability of the slope within these points, the $R^{2}$ value for set of data remains low. This is particularity so in the office where overnight conditioning maintains a set-back temperature, resulting in a rapidly changing

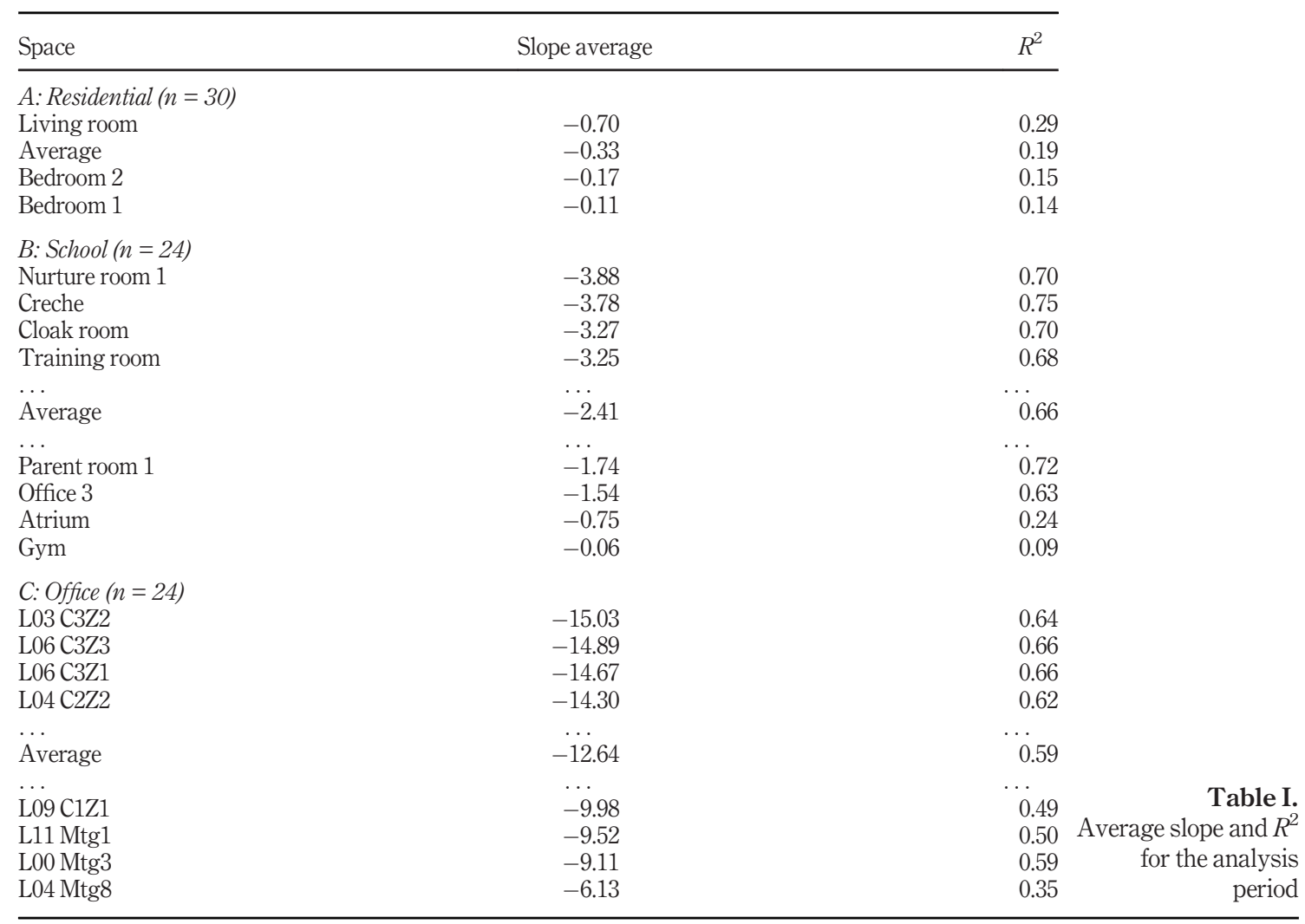

Analysis of basic building performance data

811

811


$\mathrm{F}$

$35,13 / 14$

\section{2}

Figure 8.

Difference between individual spaces and average of the whole residential building slope. While closeness of fit is low, the slope average values indicate those spaces at the extremes of the thermal responses across all monitored spaces, and therefore those with the greatest and least sensitivity to changing temperature.

\subsection{Residential building}

As only three spaces were monitored in this building, quantification of each spaces thermal response in comparison with the average of the whole building is limited. However, by using the data in conjunction with previous in-depth investigation by Dowson (2012), some initial conclusions may be reached regarding application to small sample sizes. Figure 8 shows the two most extreme spaces from the overall average (taken from Figure 5), which show very little deviation from the average, except for in the living room where the space loses heat overnight and early in the day. This corresponds to the previous study finding of thermal bridging between the space and the adjacent building, and suggests the living room responds quicker to temperature differences than other monitored spaces.

\subsection{School building}

The two spaces at the extremes of the range of thermal responses in the school are plotted in Figure 10. The position of these spaces in the school building shows that they are both externally adjacent, although respond differently to an internal and external temperature differential. The opportunity to investigate these spaces further allowed a walk-round and thermography survey to identify potential reasons for this difference.

In Nurture Room 1 two reasons for a greater than average heat loss during occupied hours were found to be thermal bridging at the junction between an internal and external wall, and its adjacency to a continuously mechanically cooled server room (Figure 9). The gym was found to be conditioned outside normal hours because of its use after school hours for activities; and given its size and amount of airflow expected for a space of this type more closely matched the change in external temperature and greater than average rate of heat loss overnight (Figure 10).

\subsection{Office building}

Of the number of monitored spaces within the office, only 31 per cent contained error-free data suitable for analysis. This suggests the need for additional pre-processing of data containing errors to enable inclusion of a far greater number of spaces. However, the number
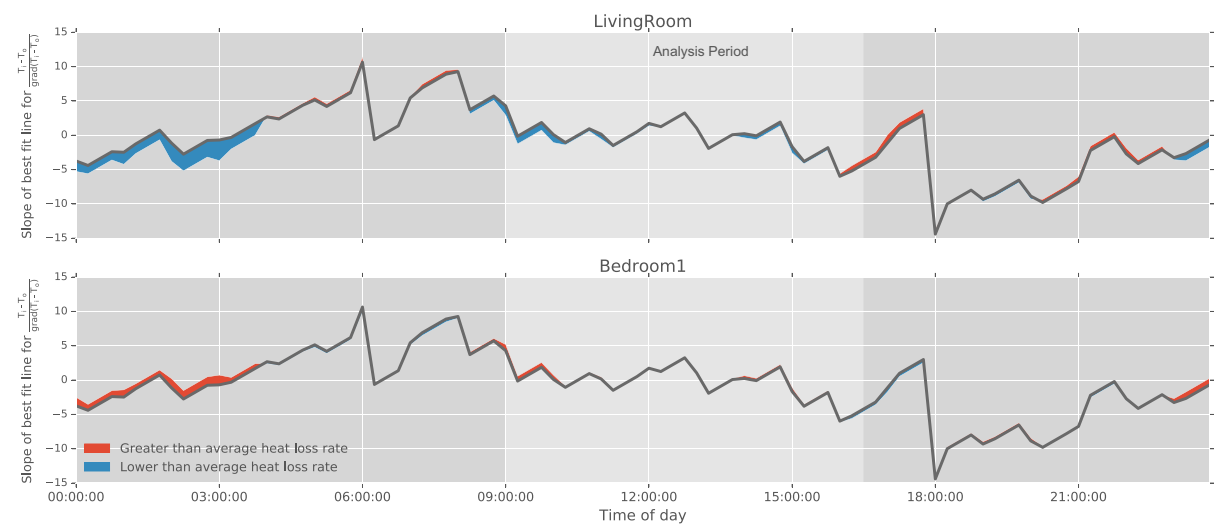
of spaces monitored here is the largest of the buildings evaluated, providing the most datarich environment in which the methodology is tested. The method of conditioning within the office is also of interest because of it use of mechanical ventilation providing a constant setback temperature outside conditioned hours, shown in Figure 11 as the rapidly changing thermal response as internal temperature drops along with building services provision of heat to maintain that setback.

Level 04 Meeting room 08 shows a greater heat loss rate than the average for all rooms, which was further investigated using lighting and small power records and then visual inspection. Greater out-of-hours use of power within the space was identified as a result of changes in use, which were discovered to be the testing of electrocution equipment instead of intended use as a meeting space. This change resulted in mechanical heating and ventilation being required to keep this space at the set-back temperature, which in turn led to a perceived greater than average heat loss rate due to this conditioning compared with other spaces during a similar time period.

\section{Conclusion}

This basic analysis of internal and external temperatures neither considers the equipment used to service the monitored spaces, the use of each space nor allows the comparison

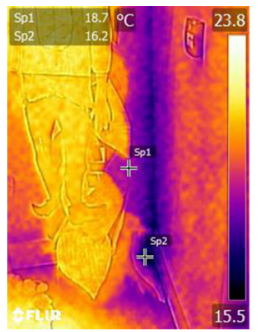

(a)

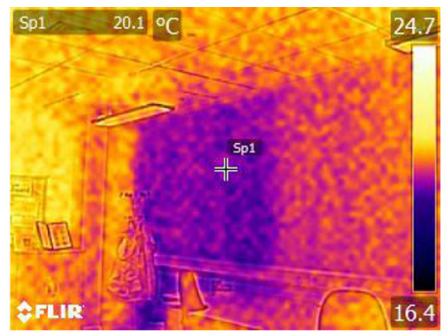

(b)

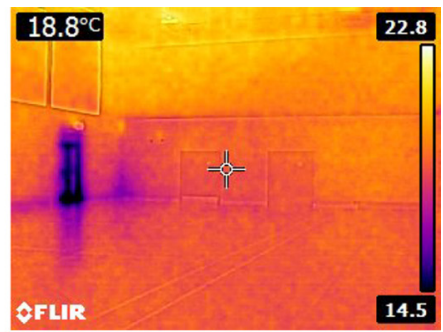

(c)
Figure 9.

Notes: (a) Nurture room 1 thermal bridging; (b) nurture room 1 cooled adjacent room; (c) gym air leakage and slight thermal bridging
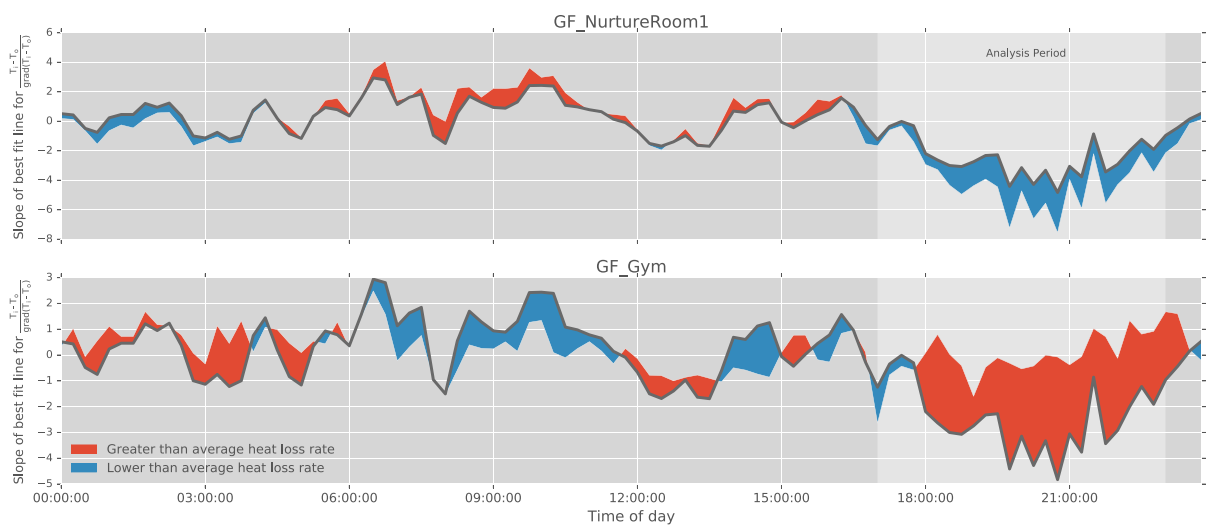

Figure 10.

Difference between individual spaces and average of the whole school building 
$\mathrm{F}$

$35,13 / 14$

814

Figure 11.

Difference between individual spaces and average of the whole office building between different buildings (as the average of the whole building's performance is the metric by which space temperature comparison is possible). However, the basic information required for this analysis and the procedure described here demonstrate the potential for use of large sets of descriptive space temperature data to indicate where there may be issues in the fabric, conditioning or use of a space in context with that spaces heating and cooling provisions.

Temperature is one of the most commonly recorded performance metrics, meaning its application for analysis is more likely than equipment performance data that many buildings would not have access to, nor have implemented. As part of the information making up what is truly "big data", basic data analysis can be used to provide a more thorough understanding of a building's behaviour and demonstrate opportunities to improve building performance through re-commissioning of building services, calibration of sensing equipment and remediation of poor fabric detailing. A key requirement of analysis is that the data used are accessible and representative, which was found to be a major limitation in this study. Of the total number of sensors from which data could have been obtained in the office test case, only 31 per cent were found to be usable due to incorrect calibration, errors in reading and non-reporting.

Comparison of alike rooms shows variation across their response to changing internal and external temperature differentials, indicating that there is potential for these differences to be further investigated and identified. For example, the three spaces in the office with the greatest rate of heat loss are on its windward side, which should not impact their performance given its double façade configuration. This indicates that there may be an issue with the construction quality on this portion of the façade.

The limitations of this particular procedure have been given, but improvements to the process which could also be applied to other descriptive building performance data are as follows:

- Analysis of data over longer periods would give a clearer and valid value for each spaces temperature difference/gradient of temperature difference. This could however also bring additional uncertainty as spaces and building services provisions may change over time.

- Higher resolution data sets would enable more confidence in the values calculated, especially in the comparative ranking of spaces.

- Basic reasons for the differences in slope have been identified as differences in internal gains between monitored spaces, potential fabric problems, locations within

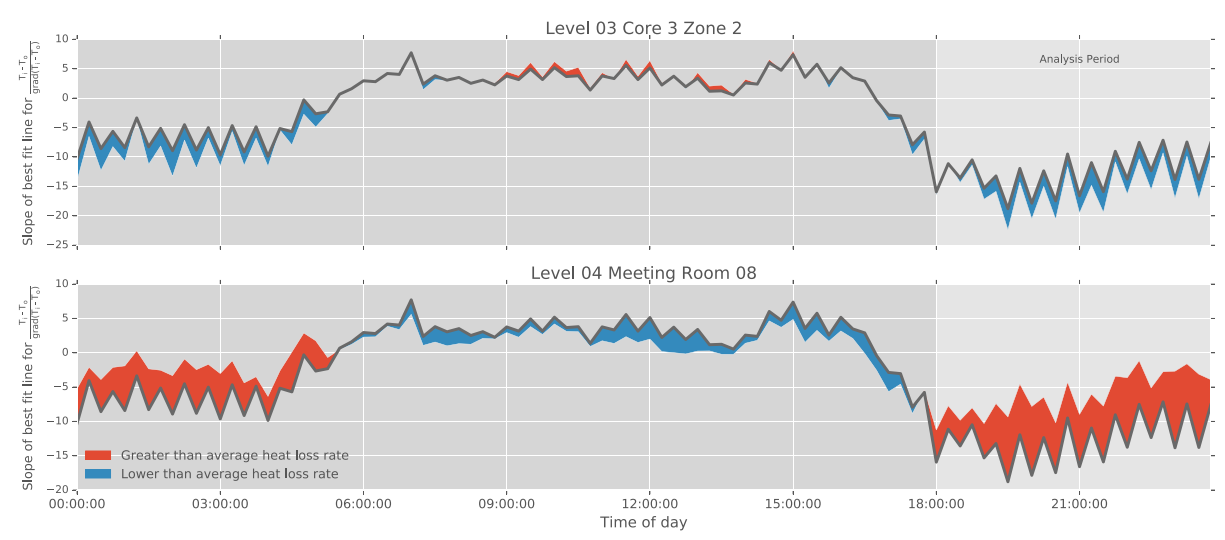


the building and mechanical conditioning. Grouping analyses into spaces externally adjacent should show more clearly where problems such as thermal bridging and poor insulation are most likely. In buildings where spaces are internal only (such as the office used here) or those where there are limited number of externally adjacent spaces, a large difference between spaces may not be seen.

- Rather than ranking an individual spaces performance based on the slope of points within its analysis period, the average difference between the space and the average for all monitored spaces may give greater indication of performance disparity.

- Application to other descriptive data sets could show where equipment or services are being used ineffectively. For example, daylight dimming controlled lighting could be assessed using lighting load and external luminance levels to show the relationship between lighting power demand and available natural lighting.

Future work will integrate this method of assessment into a Building Information Model (BIM) supported tool, utilising BMS output and an as-built model containing as-designed performance information, providing a method of evaluating a building against its intended performance.

\section{References}

Ahmad, M.W., Mourshed, M., Mundow, D., Sisinni, M. and Rezgui, Y. (2016), "Building energy metering and environmental monitoring - a state-of-the-art review and directions for future research", Energy and Buildings, Vol. 120, pp. 85-102, doi: 10.1016/j.enbuild.2016.03.059.

Arditi, D., Mangano, G. and De Marco, A. (2015), "Assessing the smartness of buildings", Facilities, Vol. 33 Nos 9/10, pp. 553-572, doi: 10.1108/F-10-2013-0076.

Baltazar-Cervantes, J.C. and Claridge, D.E. (2002), "Restoration of short periods of missing energy use and weather data using cubic spline and Fourier series approaches: qualitative analysis", Proceedings of the 13th Symposium on Improving Building Systems in Hot and Humid Climates, Houston, TX, 20-23 May, pp. 213-218.

Bordass, B., Cohen, R., Standeven, M. and Leaman, A. (2001), "Assessing building performance in use 3: energy performance of the probe buildings", Building Research \& Information, Vol. 29 No. 2, pp. 114-128, doi: 10.1080/09613210010008036.

Brown, Z. and Cole, R.J. (2009), "Influence of occupants' knowledge on comfort expectations and behaviour", Building Research \& Information, Vol. 37 No. 3, pp. 227-245, doi: 10.1080/ 09613210902794135.

Capozzoli, A., Lauro, F. and Khan, I. (2015), "Fault detection analysis using data mining techniques for a cluster of smart office buildings", Expert Systems with Applications, Vol. 42 No. 9, pp. 4324-4338, doi: 10.1016/j.eswa.2015.01.010.

Clements-Croome, D. and Johnstone, A. (2013), Intelligent Buildings: An Introduction, Chapter Intelligent Buildings Management Systems, Routledge, Abingdon.

Djuric, N. and Novakovic, V. (2009), "Review of possibilities and necessities for building lifetime commissioning”, Renewable and Sustainable Energy Reviews, Vol. 13 No. 2, pp. 486-492, doi: 10.1016/j.rser.2007.11.007.

DOE, IMT, LBNL and NREL (2016), "Standard energy efficiency data platform (SEED)", available at: http://energy.gov/eere/buildings/standard-energy-efficiency-data-platform

Doran, S. and Carr, B. (2008), "Thermal transmittance of walls of dwellings before and after application of cavity wall insulation (No. 222077)", Technical Report 222077, BRE/Energy Saving Trust.

\section{Analysis of basic building performance data}

815 
$\mathrm{F}$

$35,13 / 14$

816

Dowson, M. (2012), "Novel retrofit technologies incorporating silica aerogel for lower energy buildings", Ph.D. thesis, Brunel University, London.

Fox, M., Coley, D., Goodhew, S. and de Wilde, P. (2014), "Thermography methodologies for detecting energy related building defects", Renewable and Sustainable Energy Reviews, Vol. 40, pp. 296-310, doi: 10.1016/j.rser.2014.07.188.

Hens, H., Janssens, A., Depraetere, W., Carmeliet, J. and Lecompte, J. (2007), "Brick cavity walls: a performance analysis based on measurements and simulations", Journal of Building Physics, Vol. 31 No. 2, pp. 95-124, doi: 10.1177/1744259107082685.

Hu, J., Ogunsola, O.T., Song, L., McPherson, R.A., Zhu, M., Hong, Y. and Chen, S. (2014), "Restoration of 1-24 hour dry-bulb temperature gaps for use in building performance monitoring and analysis part I”, HVAC\&R Research, Vol. 20 No. 6, pp. 594-605, doi: 10.1080/10789669.2014.925347.

Katipamula, S. and Brambley, M. (2005), "Review article: methods for fault detection, diagnostics, and prognostics for building systems - review, part I”, HVAC\&R Research, Vol. 11 No. 2, pp. 3-25, doi: 10.1080/10789669.2005.10391123.

Khan, I., Capozzoli, A., Corgnati, S. and Cerquitelli, T. (2013), "Fault detection analysis of building energy consumption using data mining techniques", Energy Procedia, Vol. 42, pp. 557-566, doi: 10.1016/j.egypro.2013.11.057.

Kim, H., Stumpf, A. and Kim, W. (2011), "Analysis of an energy efficient building design through data mining approach", Automation in Construction, Vol. 20 No. 1, pp. 37-43, doi: 10.1016/j. autcon.2010.07.006.

Kim, Y., Schmid, T., Srivastava, M.B. and Wang, Y. (2009), "Challenges in resource monitoring for residential spaces", Proceedings of the First ACM Workshop on Embedded Sensing Systems for Energy-Efficiency in Buildings, BuildSys '09, ACM, New York, NY, pp. 1-6, doi: 10.1145/ 1810279.1810281.

Levac, D., Colquhoun, H. and O'Brien, K.K. (2010), "Scoping studies: advancing the methodology", Implementation Science, Vol. 5 No. 1, pp. 1-9, doi: 10.1186/1748-5908-5-69.

Marincioni, V., May, N. and Altamirano-Medina, H. (2015), "Parametric study on the impact of thermal bridges on the heat loss of internally insulated buildings", Energy Procedia, Vol. 78, pp. 889-894, doi: 10.1016/j.egypro.2015.11.013.

Martínez-Molina, A., Tort-Ausina, I., Cho, S. and Vivancos, J.-L. (2016), "Energy efficiency and thermal comfort in historic buildings: a review", Renewable and Sustainable Energy Reviews, Vol. 61, pp. 70-85, doi: 10.1016/j.rser.2016.03.018.

McKinney, W. (2010), "Data structures for statistical computing in Python", Proceeding 9th Python in Science Conference, pp. 51-56, available at: http://conference.scipy.org/proceedings/scipy2010/ mckinney.html

Menezes, A., Cripps, A., Bouchlaghem, D. and Buswell, R. (2012), "Predicted vs. actual energy performance of non-domestic buildings: using post-occupancy evaluation data to reduce the performance gap”, Applied Energy, Vol. 97, pp. 355-364, doi: 10.1016/j.apenergy.2011.11.075.

Mydin, M.A.O., Ramli, M. and Awang, H. (2012), "Factors of deterioration in building and the principles of repair”, Analele Universitaôts ii “Eftimie Murgu” Reşiț a, Vol. 19, pp. 345-352.

Peña, M., Biscarri, F., Guerrero, J.I., Monedero, I. and León, C. (2016), "Rule-based system to detect energy efficiency anomalies in smart buildings, a data mining approach", Expert Systems with Applications, Vol. 56, pp. 242-255, doi: 10.1016/j.eswa.2016.03.002.

Pegg, I.M., Cripps, A. and Kolokotroni, M. (2007), "Post-occupancy performance of five low-energy schools in the UK", AHSHRAE Transactions, Vol.113, pp. 3-11.

Preiser, W.F.E. (2003), "Continuous quality improvement through postoccupancy evaluation feedback", Journal of Corporate Real Estate, Vol. 5 No. 1, pp. 42-56, doi: 10.1108/14630010310811993.

Seem, J.E. (2007), "Using intelligent data analysis to detect abnormal energy consumption in buildings", Energy and Buildings, Vol. 39 No. 1, pp. 52-58, doi: 10.1016/j.enbuild.2006.03.033. 
Taileb, A. and Dekkiche, H. (2015), "Infrared imaging as a means of analyzing and improving energy efficiency of building envelopes: the case of a LEED gold building", Procedia Engineering, Vol. 118, pp. 639-646, doi: 10.1016/j.proeng.2015.08.497.

Taleb, N.N. (2013), "Beware the errors of 'Big Data”, available at: www.wired.com/2013/02/big-datameans-big-errors-people/

Analysis of basic building performance data

The AECB (2013), "Low energy building database", available at: www.lowenergybuildings.org.uk/

The Digital Catapult and Innovate UK (2016), "Building data exchange", available at: https:// buildingdataexchange.org.uk/

Theodosiou, T.G. and Papadopoulos, A.M. (2008), "The impact of thermal bridges on the energy demand of buildings with double brick wall constructions", Energy and Buildings, Vol. 40 No. 11, pp. 2083-2089, doi: 10.1016/j.enbuild.2008.06.006.

Waters, L., Wilkes, E. and Goodright, V. (2015), "Energy consumption in the UK - Chapter 5: service factsheet", Technical Report, Department of Energy \& Climate Change.

Way, M. and Bordass, B. (2005), "Making feedback and post-occupancy evaluation routine 2: soft landings - involving design and building teams in improving performance", Building Research \& Information, Vol. 33 No. 4, pp. 353-360, doi: 10.1080/09613210500162008.

Way, M., Bordass, B., Leaman, A. and Bunn, R. (2009), "The soft landings framework: for better briefing, design, handover and building performance in-use", Technical Report, BSRIA.

White, E.T. (1989), Building Evaluation, Chapter Post-Occupancy Evaluation from the Client's Perspective, Springer US, Boston, MA, pp. 19-34.

Yu, Z., Haghighat, F. and Fung, B.C.M. (2015), "Advances and challenges in building engineering and data mining applications for energy-efficient communities", Sustainable Cities and Society, doi: 10.1016/j.scs.2015.12.001.

Zero Carbon Hub (2014), "Closing the gap between design and as-built performance: evidence review report", Technical Report, Zero Carbon Hub.

Zhou, K., Fu, C. and Yang, S. (2016), "Big data driven smart energy management: from big data to big insights", Renewable and Sustainable Energy Reviews, Vol. 56, pp. 215-225, doi: 10.1016/j. rser.2015.11.050.

\section{Corresponding author}

Tristan Gerrish can be contacted at: tristan.gerrish@burohappold.com

For instructions on how to order reprints of this article, please visit our website:

www.emeraldgrouppublishing.com/licensing/reprints.htm

Or contact us for further details: permissions@emeraldinsight.com 